from Indiana University, the National Capital Area Political Science Association Pi Sigma Alpha Award, the APSA Committee on the Status of Blacks Award for service and leadership, and APSA's Charles E. Merriam Award. He was also honored by the American Political Science Association with the establishment of the Evron M. Kirkpatrick Fund which supports the Pi Sigma Alpha Oral History Project and a monograph series on the craft of political science.

\section{Comment on the NEH Report Humanities in America}

Editor's Note: The following paper was prepared by the Policy Planning Committee of the National Humanities Alliance, and permission has been given for reprinting in PS. The APSA is a member of the National Humanities Alliance.

The release of Humonities in America, a report by NEH Chair Lynne V. Cheney. prepared in response to a 1985 Congressional mandate, will surely stimulate consideration of the achievements, shortcomings, and future of the humanities. In the hope of assisting public discussion, the Policy Planning Committee and the Board of Directors of the National Humanities Alliance (NHA) wish to call attention to several issues readers of the report should note. We divide our remarks concerning the report into three sections, indicating points of agreement first, statistics requiring cautious interpretation second, and points of disagreement last.

The NHA is an independent federation of 54 learned and professional societies, organizations representing museums, libraries, historic organizations, and other non-profit institutions committed to enhancing the place of humanistic inquiry in American life and to assisting in development of federal policies for the support of research, teaching, and other humanities activities. A list of NHA's members is attached. The views expressed in this docu- ment should not be taken to be those of every member of the Alliance.

We support Mrs. Cheney's recognition of the growth of public interest in exhibitions, public humanities programs, musical and theatrical performances, and media programming of the past two decades.

\section{College and university \\ ensollments have remained} stable, while ensollments in some husnamities cousses

\section{have increased.}

Our museum constituency takes particular satisfaction in the acknowledgment of the important educational role played by their institutions

We join her in praising the achievements of the state humanities councils in public programming. The rich variety of state council programs has made an indispensable contribution to the "parallel school" of public learning to which Mrs. Cheney refers.

Finally, we agree with her comments on the potential of humanities programming in the mass media, particularly in television and film.

\section{II}

However, we find the report's statistics $(p .4)$ regarding the study of the humanities in colleges and universities incomplete. Because the cited statistics focus on the beginning and end points of a complex period (1966 and 1986), the report overlooks a number of significant changes within the period. Using only these statistics obscures the fact that college and university enrollments did not increase uniformly throughout the period and minimizes growth in humanities enrollments since 1980. Consequently, the report draws a conclusion that seems to us unduly negative. 
indeed, since 1980, college and university enrollments have remained relatively stable, while enrollments in some humanities courses have increased. For example. according to information gathered by the Modern Language Association, enrollments in foreign language rose $8 \%$ between 1980 and 1986. Similarly, an MLA survey showed that the vast majority of English departments reported stable or growing numbers of majors from 1980 to 1983.

\section{Srecialization in scholar

ship is weither new non a

\section{wossisome develofmest.}

Statistics from one institution illustrate the importance of examining enroliment figures closely. The philosophy department at the University of Delaware reports that the number of its majors remained small from 1967 to 1987, ranging between 20 and 40 each year. However, enrollments in philosophy courses, none of which are institutional requirements, increased steadily; in 1987 they were $75 \%$ higher than in 1977 and more than 300 percent higher than in 1967. Less systematic surveys by other humanities departments in a variety of institutions suggest to us that this pattern-many students but few majors - is a familiar one. (As this example shows, students enroll in humanities courses even when the courses are not required. Therefore, care must also be taken in ascribing significance to the $a b$ sence of college and university requirements in the humanities (See report, $p$. 5]).

The point we wish to make is this. If enrollment statistics are used to measure the health of the humanities in American colleges and universities, one must undertake a more detailed analysis of enrollment trends-not only in greater detail for the twenty year period discussed in the report but over a longer period as well. In addition, one would expect such an analysis to give special attention to the recent upward movement in enrollments in humanities courses.
III

Finally, we note points of disagreement. The first is the report's assertion that in creasingly narrow specialization in both topic and method has robbed the humanities of "their significance and centrality" (pp. 8-9) and the report's recommendation that "those who fund, publish, and evaluate research should encourage work of general significance" ( $p$. 32). If what is meant here is the discouragement of speclalized research, then we believe that this recommendation rests upon a profound misunderstanding of scholarship, specialization, and higher education. Specialization in scholarship, in our view, is neither a new nor a worrisome development. It is an essential, defining aspect of higher education. The authors of a forthcoming study of the humanities in higher education, six distinguished scholars who direct humanities centers, agree that to identify the specialization of research as a problem is misguided. They go on to say:

research must be specialized. Since it consists of learning more than is already known about a topic, it must focus its ef. forts specifically and intensely, in uncommon fashion, to make progress. Almost by definition, research is specialized, aiming to delve more deeply or examine more closely than hitherto. (George Levine. Peter Brooks, Jonathan Culler, Marjorie Garber. Ann Kaplan, and Catharine Stımpson, "Speaking for the Humanities, " p. 30).

In the light of the report's concern about specialization, it is not surprising that scant attention is given to the NEH's vital contributions to scholarship and teaching. Through NEH grants to individual scholars, institutions sponsoring major conferences, editors preparing new translations and critical editions, and summer and year-long seminar participants, the NEH has provided the major source of funds not only for scholarship in the humanities but also for the improvement of teaching. Without $\mathrm{NEH}$ support for research in the humanities, scholarship would be immeasurably impeded, teaching would suffer, and the intellectual life of our nation would be very much the poorer.

Likewise, in praising the work of state humanities councils, there is no mention of 
the NEH requirement that scholars be involved with every project and substantially represented on each state council. These provisions have provided many occasions for creative collaboration. As a consequence, state councils represent a happy marriage not only between local initiative and federal support but also between scholars and the general public.

Finally, we disagree with the claim that "viewing humanities texts as though they were primarily political documents is the most noticeable trend in academic study of the humanities today. Truth and beauty and excellence are regarded as irrelevant: questions of intellectual and aesthetic quality, dismissed." Doubtless there are some scholars, on the political left and on the right, who wish this were so. Such a sweeping assertion, however, overlooks the complexity and range of contemporary humanities scholarship and the methodologies scholars employ. Attending to the social and political dimensions of humanities texts does not imply a denigration of their aesthetic or intellectual value, for such texts reward close reading from many perspectives. The enlargement of the canon to include oral histories. women philosophers, and African novelists has helped scholars and students alike to discover new truths, new beauties, and new excellences.
Mrs. Cheney's report raises a number of important questions. While we disagree with some of her conclusions, we share her commitment to enhancing opportunities that will help all citizens gain access to enjoy and learn from the humanities. The NHA and its members will continue to study and discuss ways of strengthening teaching, fulfilling the multiple goals of a

Attending to the rocial and folitical dimensions of humanities texts does not imply a denifration of their aesthetic on

college education, and determining the most effective curricular arrangements. We look forward to participating in a vigorous debate on these and other matters affecting the humanities. Finally, we look forward to continuing our support for the $\mathrm{NEH}$, its staff and programs. 